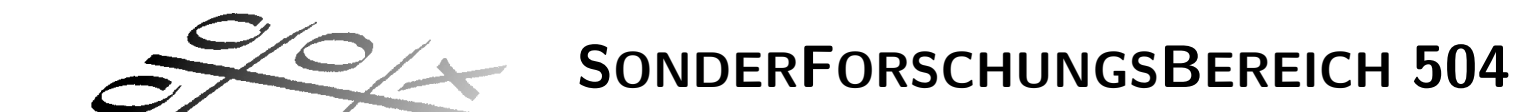

Rationalitätskonzepte,

Entscheidungsverhalten und

ökonomische Modellierung

\begin{tabular}{|c|}
\hline No. 08-08 \\
Are the Treasures of Game Theory Ambiguous? \\
Jürgen Eichberger* \\
and David Kelsey**
\end{tabular}

May 2008

Financial support from the Deutsche Forschungsgemeinschaft, SFB 504, at the University of Mannheim, is gratefully acknowledged.

*Sonderforschungsbereich 504, email: juergen.eichberger@awi.uni-heidelberg.de

** Department of Economics, The University of Birmingham, email: D.KELSEY@BHAM.AC.UK

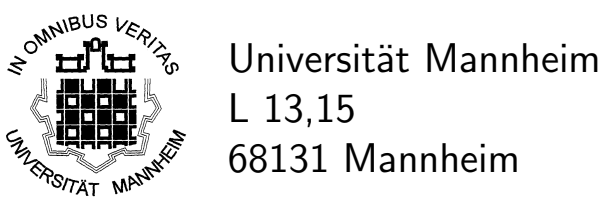




\title{
Are the Treasures of Game Theory Ambiguous?*
}

\author{
Jürgen Eichberger \\ Department of Economics, \\ Universität Heidelberg, Germany
}

\author{
David Kelsey \\ School of Business and Economics \\ University of Exeter, England
}

24th May 2008

This version: May 27, 2008

\begin{abstract}
Goeree \& Holt (2001) observe that, for some parameter values, Nash equilibrium provides good predictions for actual behaviour in experiments. For other payoff parameters, however, actual behaviour deviates consistently from that predicted by Nash equilibria. They attribute the robust deviations from Nash equilibrium to actual players' considering not only marginal gains and losses but also total pay-offs. In this paper, we show that optimistic and pessimistic attitudes towards strategic ambiguity may induce such behaviour.
\end{abstract}

JEL Classification: C72, D81.

Keywords: Ambiguity, coordination games, experiments, traveller's dilemma, matching pennies, optimism.

Adress for Correspondence: Prof. Dr. Jürgen Eichberger, Department of Economics, University of Heidelberg, Grabengasse 15, D-69117 HEIDELBERG, GERMANY.

\footnotetext{
* For comments and discussion we would like to thank Vince Crawford, Miguel Fonseca, Todd Kaplan, Tim
} Worrall and participants in seminars at Exeter, Keele and St. Andrews. 


\section{INTRODUCTION}

Nash equilibrium (henceforth NE) is the most widely used equilibrium concept in game theory. Though a large and growing number of experimental studies indicate its weaknesses, it has proved difficult to find systematic patterns in the deviations from NE. Given this, we believe that it is worth considering alternatives.

Goeree \& Holt (2001) (henceforth GH) published an article with the provocative title "Ten Little Treasures of Game Theory and Ten Intuitive Contradictions" in which they claim that "for each of these ten games there is an experimental treatment in which behaviour conforms nicely to predictions of NE" but where "a change in the payoff structure produces a large inconsistency between theoretical predictions and observed behaviour". ${ }^{1}$ In the present paper we restrict attention to the five one-shot games, which GH studied. We argue that many of the "inconsistencies" in these games can be explained by ambiguity.

Ambiguity describes situations where individuals cannot or do not assign subjective probabilities to uncertain events. This may be because the problem is complex or unfamiliar. There is by now considerable experimental evidence which shows that individuals treat ambiguous decisions differently from risks with known probabilities. The best known example is the Ellsberg paradox, Ellsberg (1961). ${ }^{2}$ There is also experimental evidence that behaviour in games is affected by ambiguity. Colman \& Pulford (2007) present some experimental evidence that ambiguity affects behaviour in games but do not test any particular theories. Eichberger, Kelsey \& Schipper (2008b) use a similar theory of ambiguity to the present paper. They test it on games with strategic complements or substitutes and find the evidence is broadly supportive.

We believe that ambiguity may be present in experimental games since the relevant uncertainty is the strategy choice of one's opponent. Human behaviour is not intrinsically easy to predict. It is plausible that there may be ambiguity in GH's experiments since each game was

\footnotetext{
1 Goeree \& Holt (2001) p. 1402.

2 This has been confirmed by the subsequent experimental literature, see for instance Camerer \& Weber (1992) and Cohen, Jaffray \& Said (1985).
} 
only played once. Hence subjects did not have time to become familiar with the game or the behaviour of their opponents.

In this paper, each player views the strategy choice by his/her opponents as potentially ambiguous. We use a model of uncertainty axiomatised by Chateauneuf, Eichberger \& Grant (2007), (henceforth CEG), in which ambiguity is represented by non-additive beliefs. Applying this theory to games, implies that players will maximize an objective function which consists of a weighted average of the equilibrium pay-off, the best pay-off and the worst pay-off for any given strategy. Thus players react to ambiguity partly in an optimistic way by over-weighting good outcomes and partly in a pessimistic way by over-weighting bad outcomes. Subsection 2.1 will introduce these preferences, provide some intuition for the parameters of this model and point to the experimental literature, which tries to estimate them.

Organization of the Paper The next section describes our basic model of ambiguity in games. Subsection 2.3 defines an Equilibrium under Ambiguity (EUA), the equilibrium notion which will be used in this paper. In section 3 we argue that GH's results on one-shot games can be explained by ambiguity. In Section 4 we discuss competing theories such as Quantal Response Equilibrium or the Cognitive Hierarchy Model and section 5 concludes. The appendix contains proofs of those results not proved in the text.

\section{STRATEGIC AMBIGUITY}

This section introduces our model of ambiguity and uses it as the basis of a solution concept for normal form games.

\section{$2.1 \quad$ Non-additive beliefs}

In the present paper we restrict attention to ambiguity in 2-player games, which requires the following notation. A 2-player game $\Gamma=\left\langle\{1,2\} ; S_{1}, S_{2}, u_{1}, u_{2}\right\rangle$ consists of players, $i=1,2$, finite pure strategy sets $S_{i}$ and payoff functions $u_{i}\left(s_{i}, s_{-i}\right)$ for each player. The space of all strategy profiles is denoted by $S$. The notation, $s_{-i}$, denotes the strategy chosen by $i$ 's opponent. The set of all strategies for $i$ 's opponent is $S_{-i}$. We shall adopt the convention that female 
pronouns (she, her etc.) denote player 1 and male pronouns denote player $2 .^{3}$

Beginning with Schmeidler (1989), ambiguous beliefs have been modelled as capacities, which are similar to subjective probabilities except that they are not necessarily additive. We shall use a model of ambiguity from CEG, which has the advantage that it is parsimonious in the number of parameters. This theory represents beliefs by a neo-additive capacity $\nu$ defined by:

$$
\nu(A \mid \alpha, \delta, \pi)= \begin{cases}1 & \text { for } A=S_{-i}, \\ \alpha \delta+(1-\delta) \pi(A) & \text { for } \emptyset \varsubsetneqq A \varsubsetneqq S_{-i}, \\ 0 & \text { for } A=\varnothing,\end{cases}
$$

where $\alpha, \delta \in[0,1], \pi$ is an additive probability distribution $\pi$ on $S_{-i}$ and $\pi(A):=\sum_{s_{-i} \in A} \pi_{i}\left(s_{-i}\right)$. They show that preferences may be represented in the form:

$V_{i}\left(s_{i} ; \alpha, \delta, \pi\right)=\delta\left[\alpha \max _{s_{-i} \in S_{-i}} u_{i}\left(s_{i}, s_{-i}\right)+(1-\alpha) \min _{s_{-i} \in S_{-i}} u_{i}\left(s_{i}, s_{-i}\right)\right]+(1-\delta) \cdot \mathbf{E}_{\pi} u_{i}\left(s_{i}, s_{-i}\right)$, where $\mathbf{E}_{\pi} u_{i}\left(s_{i}, s_{-i}\right)$, denotes a conventional expectation taken with respect to the probability distribution $\pi .^{4}$

One can interpret $\pi$ as the decision-maker's belief. However (s)he may not be fully confident in this belief. Thus it is an ambiguous belief. His/her confidence is modelled by the weight $(1-\delta)$ given to the expected payoff $\mathbf{E}_{\pi} u_{i}\left(s_{i}, s_{-i}\right)$. Or equivalently $\delta$ can be interpreted as a measure of the ambiguity the decision-maker perceives. The highest (resp. lowest) possible level of ambiguity corresponds to $\delta=1$, (resp. $\delta=0$ ). Ambiguity-attitude is measured by $\alpha$, which represents the optimism/pessimism of the decision maker. Purely optimistic preferences are given by $\alpha=1$, while the highest level of pessimism occurs when $\alpha=0$. If $0<\alpha<1$, the individual is neither purely ambiguity-averse nor purely ambiguity-loving, since (s)he responds to ambiguity partly in an optimistic way by over-weighting good outcomes and partly in a pessimistic way by over-weighting bad outcomes.

3 Of course this convention is for convenience only and bears no relation to the actual gender of subjects in GH's experiments.

4 For simplicity, we will write, in slight abuse of notation, $V_{i}\left(s_{i} ; \alpha, \delta, \pi\right)$ instead of $V_{i}\left(s_{i} ; \nu(\cdot \mid \alpha, \delta, \pi)\right)$. 


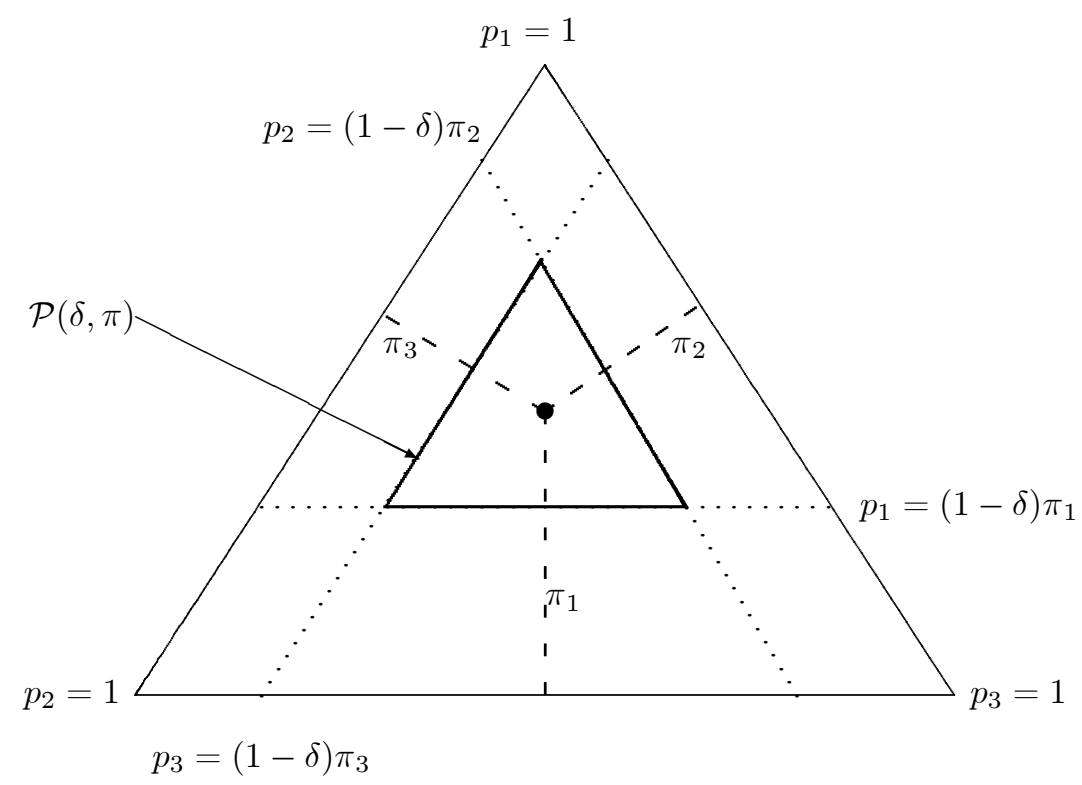

Figure 1. The set $\mathcal{P}(\delta, \pi)$ 
A possible interpretation is that the optimism parameter, $\alpha$, is a personal characteristic of the decision maker like his/her risk preferences. In contrast, the degree of ambiguity, $\delta$, may depend on the situation. In particular, one would expect there to be more ambiguity when players interact for the first time. Growing familiarity with the game and the behaviour of opponents is likely to reduce ambiguity.

CEG also show that these preferences may be represented in the multiple priors form: ${ }^{5}$

$$
V_{i}\left(s_{i} ; \alpha, \delta, \pi\right)=\alpha \max _{p \in \mathcal{P}} \mathbf{E}_{p} u_{i}\left(s_{i}, s_{-i}\right)+(1-\alpha) \min _{p \in \mathcal{P}} \mathbf{E}_{p} u_{i}\left(s_{i}, s_{-i}\right),
$$

where $\mathcal{P}:=\left\{p \in \Delta\left(S_{-i}\right): p \geqslant(1-\delta) \pi\right\}$. For the case of one opponent with three pure strategies, Figure 1 shows the set of probability distributions $\mathcal{P}(\delta, \pi)$.

The multiple priors representation in equation (1) can be interpreted as follows. When an individual perceives a situation as ambiguous (s)he considers more than one probability distribution to be possible. He/she reacts to ambiguity partly in an optimistic way by using the most favourable possible probability and partly in a pessimistic way by using the least favourable distribution.

\subsection{Evidence on Individual Decisions}

Tversky \& Wakker (1995) study the relationship between decision weights and attitudes towards risk and characterize the possibility and certainty effects. A majority of individuals appear to behave cautiously when there is ambiguity. Following Wakker (2001), who relates such behaviour to a generalized version of the Allais paradox, we shall refer to such cautious behaviour as pessimism. This article surveys the relevant experimental literature, which shows, that a minority of individuals respond to ambiguity in the opposite way, i.e. they display optimism.

Experiments on decision-making with known probabilities have shown that individuals tend to overweight both high and low probability events. As a result the decision weights assigned to events are an inverse S-shaped function compared to the given probability distribution, (see for instance, Gonzalez \& Wu (1999) and Abdellaoui (2000)). This can be explained by insensitivity

\footnotetext{
5 Gilboa \& Schmeidler (1989) axiomatised the multiple priors model, which represents ambiguous beliefs by sets of probability distributions. Multiple priors and non additive beliefs produce related models of ambiguity. However they are not, in general, identical.
} 
of perception in the middle of the range. For instance, the change from a probability of 0.55 to 0.60 is not perceived as great as the change from 0 to 0.05 .

If probabilities are not known, a similar phenomena has been found (see, Kilka \& Weber (2001)). Individuals overweight both highly likely and highly unlikely events. (In this case the likelihood of events is subjective.) This produces a pattern of decision weights like that illustrated in Figure 2. The curved line represents the decision weights of a typical experimental subject and the $45^{\circ}$ line represents SEU beliefs for comparison. This diagram is based on observations that subjects are willing to take courses of action, which yield high outcomes in unlikely events but refuse to accept even a small chance of bad outcomes. The more unfamiliar the source of uncertainty is the lower is the elevation of the curve, i.e. the curve shifts downwards in less familiar situations. This can be interpreted as an effect of ambiguity.

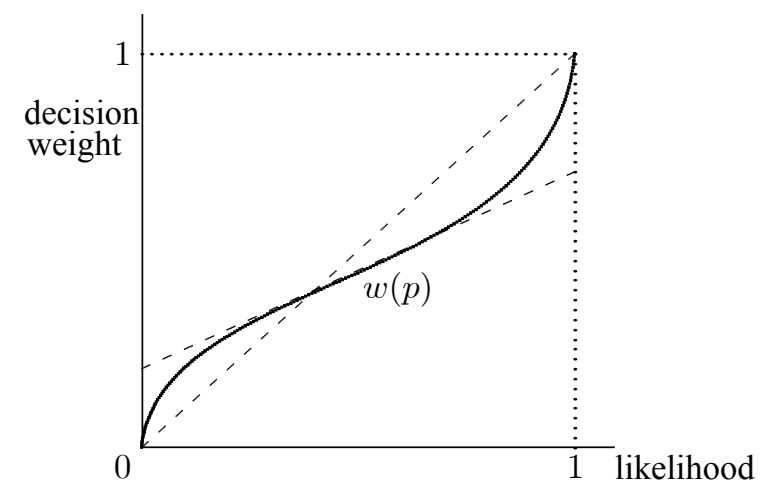

Figure 2. Inverse-S decision weights

Kilka \& Weber (2001) report an experimental study of choices in financial markets, which was able to distinguish beliefs from decision weights. They found that decision weights deduced from actual choices were markedly non-additive. Moreover the weighting scheme of a neoadditive capacity provides a simple version of an inverse-S shaped function relating beliefs, $p$, to decision weights, $w(p)$.

$$
w(p):= \begin{cases}1 & \text { for } p=1 \\ \delta \alpha+(1-\delta) \cdot p & \text { for } 0<p<1 \\ 0 & \text { for } p=0\end{cases}
$$

This weighting scheme is illustrated in Figure 3. It can be seen as a piecewise linear approxi- 


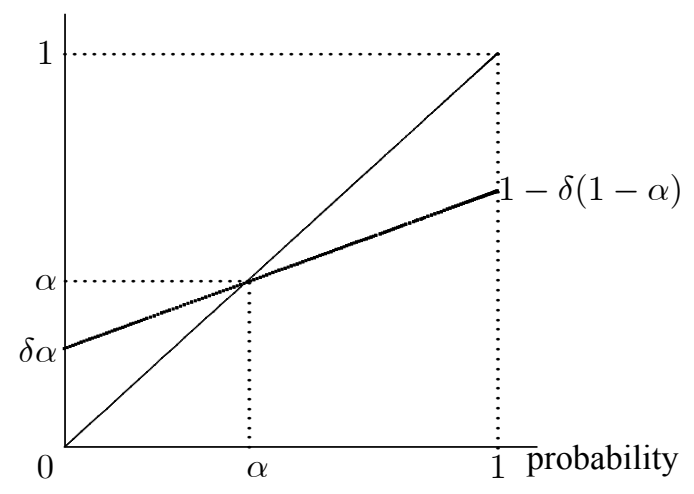

Figure 3. Neo-additive capacity

mation to that in Figure 2.

Kilka \& Weber (2001) used their data to estimate degrees of optimism and ambiguity separately. In terms of our notation, they report the following values:

\begin{tabular}{|l|l|c|c|}
\hline & \multicolumn{1}{|c|}{$\alpha$} & $\delta$ & $\alpha \delta$ \\
\hline Average & 0.5 & 0.52 & 0.26 \\
\hline Max. & 0.62 & 0.61 & 0.34 \\
\hline Min. & 0.4 & 0.41 & 0.18 \\
\hline
\end{tabular}

The values of both optimism $\alpha$ and ambiguity $\delta$ vary around 0.5 with deviations of 0.1 .

In this paper we shall provide an explanation for experimental evidence assuming that individuals have CEU preferences with parameters compatible with the experimental data from Kilka \& Weber (2001). The evidence suggests that we should consider $0.4 \leqslant \alpha \leqslant 0.62$ and $0.41 \leqslant \delta \leqslant 0.61$. We say that if $\alpha$ and $\delta$ satisfies these inequalities that they lie in the $K W$ range. ${ }^{6}$

\subsection{Equilibrium under Ambiguity}

We shall use a solution concept based on Dow \& Werlang (1994). ${ }^{7}$ Formally, we assume that each player maximizes his/her expected payoff with respect to a non-additive belief. In equilibrium, beliefs have to be reasonable in the sense that each player "believes" that the opponents

\footnotetext{
$6 \quad$ In the present paper we shall assume that $\alpha$ and $\delta$ are distributed independently. We believe independence to be a reasonable approximation. In any event, it is not possible to estimate the joint distribution from the data in Kilka \& Weber (2001).

7 Dow \& Werlang (1994) assumed ambiguity-aversion. Their solution concept was later generalized to an arbitrary number of players in Eichberger \& Kelsey (2000) and extended to include optimistic behavior in Eichberger \& Kelsey (2006).
} 
play best responses. To model this we require that the support of any given player's beliefs contain only best responses of the other players. Denote by $R_{i}\left(\nu_{-i}\right)=\arg \max \left\{V_{i}\left(s_{i}, \nu_{-i}\right) \mid s_{i} \in\right.$ $\left.S_{i}\right\}$ the best response correspondence of player $i$, given beliefs represented by the capacity $\nu_{-i}$ on $S_{-i}$.

Most theories of ambiguity are formulated for single person decisions. To study ambiguity in games it is necessary to extend them to allow for the interactions between different decisionmakers. In the absence of ambiguity, each player is assumed to choose a strategy which maximizes his/her expected payoff with respect to beliefs which are compatible with the strategies of their opponents. Most equilibrium notions rest on some degree of consistency between actual behaviour and beliefs, since players are likely to adapt their beliefs if they observe behaviour which contradicts them. In the presence of ambiguity, perfect consistency is unlikely since there do not exist non-additive randomising devices, which prevents us from constructing strategies, corresponding precisely to ambiguous beliefs. We consider games where each player believes that the strategy choice of his/her opponents is possibly ambiguous. ${ }^{8}$ An equilibrium is a situation where players behave optimally relative to their beliefs.

Definition 2.1 A pair of capacities $\nu^{*}=\left\langle\nu_{1}^{*}, \nu_{2}^{*}\right\rangle$ is an Equilibrium Under Ambiguity (EUA) if

$$
\varnothing \neq \operatorname{supp} \nu_{1}^{*} \subseteq R_{1}\left(\nu_{2}^{*}\right) \text { and } \varnothing \neq \operatorname{supp} \nu_{2}^{*} \subseteq R_{1}\left(\nu_{1}^{*}\right) .{ }^{9}
$$

If $s_{i}^{*} \in \operatorname{supp} \nu_{i}^{*}$ for $i=1,2$, we say that $s^{*}=\left\langle s_{1}^{*}, s_{2}^{*}\right\rangle$ is an equilibrium strategy profile. If $\operatorname{supp} \nu_{i}^{*}$ contains a single strategy profile for $1=1,2$ we say that it is a pure equilibrium, otherwise we say that it is mixed. ${ }^{10}$

A mixed equilibrium, where the support contains multiple strategy profiles, should be interpreted as an equilibrium in beliefs rather than randomisations.

\footnotetext{
8 There are other possible modelling choices, for instance, one could consider there is ambiguity about the opponents' type.

9 Existence of equilibrium can be proved in a standard way using fixed-point theorems, see Dow \& Werlang (1994), Eichberger \& Kelsey (2000) and Eichberger, Kelsey \& Schipper (2008a).

10 Our aim is to modify Nash equilibrium by allowing for the possibility that players may view their opponents behavior as ambiguous. If beliefs were additive, then in a 2-player game, Definition 2.1 would coincide with Nash equilibrium. In this sense we have modified Nash equilibrium to allow for ambiguity.
} 


\subsection{Support of Ambiguous Beliefs}

There is more than one way to extend the notion of a support from probability distributions to capacities. This definition determines how tight the relationship between beliefs and actual behaviour is. Definition 2.1 requires the strategies in the support of a given player's equilibrium belief be best responses. However it is ambiguous whether the opponents play best responses. As result, in addition, the best and worst possible plays by one's opponent are taken into account when evaluating a strategy. Decision-relevant strategies outside the support can be interpreted as events a player views as unlikely but which, due to ambiguity cannot be completely ruled out.

Several solution concepts for games with strategic ambiguity have been suggested, (see for instance Marinacci (2000) and Lo (1996)). The main difference between the various solution concepts is that they use different support notions. Thus the definition of support deserves careful consideration.

Definition 2.2 We define the support of the neo-additive capacity $\nu(\cdot \mid \alpha, \delta, \pi)$ by $\operatorname{supp} \nu=$ $\operatorname{supp} \pi$.

As explained above a neo-additive capacity is intended to represent a situation where the decision-maker's belief is represented by the additive probability distribution $\pi$ but (s)he is not fully confident in this belief. Given this it is plausible that the support of $\nu$ should coincide with that of $\pi$. Eichberger \& Kelsey (2006) show that, for a neo-additive capacity $\nu(\cdot \mid \alpha, \delta, \pi)$,

$$
\operatorname{supp} \nu=\bigcap_{p \in \mathcal{P}} \operatorname{supp} p,^{11}
$$

where $\mathcal{P}$ is the set of probability distributions defined in equation (1). ${ }^{12}$

1 This definition of support essentially coincides with the inner support notion in Ryan (1997).

12 Much of the existing literature on ambiguity in games has explicitly or implicitly restricted attention to the case of pessimistic players. In the present paper, an important part of our explanation of behavior in experimental games relies to a large extent on optimistic responses to ambiguity. It is, therefore, necessary to reconsider the support notions put forth in the previous literature. For a more detailed discussion of the relation of our proposal to earlier support notions see Eichberger \& Kelsey (2006). 


\section{EXPERIMENTAL GAMES}

Goeree \& Holt (2001) present evidence that NE is a good predictor in some games but not in others. In particular they consider five one-shot games, in which there is evidence in favour of NE. However, in each case, a seemingly irrelevant parameter change produces the opposite result. In this section we argue that much of this evidence can be explained by ambiguity. For expository reasons we shall discuss the experiments in a different order to GH. To avoid undue repetition, we shall discuss the first example in detail and discuss the remaining cases more briefly.

\subsection{The Kreps Game}

The impact of ambiguity is illustrated by the Kreps game, which is an asymmetric coordination game with a safe strategy for Player $2, \mathrm{NN} .{ }^{13}$ The normal form of the game is described in the following table:

\section{Game A}

\section{Player 2}

\begin{tabular}{|c|c|c|c|c|c|}
\hline \multirow{3}{*}{ lays } & & $L \quad(26 \%)$ & $(8 \%)$ & $\mathrm{NN} \quad(68 \%)$ & $(0 \%)$ \\
\hline & $(68 \%)$ & 200,50 & 0,45 & 10,30 & $20,-250$ \\
\hline & $(32 \%)$ & $0,-250$ & $10,-100$ & 30,30 & 50,40 \\
\hline
\end{tabular}

The numbers in brackets denote the number of subjects playing the respective strategies in GH's experiment. The only two Nash equilibria in pure strategies are $\langle T, L\rangle$ and $\langle B, R\rangle$. There is also a mixed strategy equilibrium, in which Player 2 chooses $M$ and $L$ each with positive probability. The only strategy not played in any NE is NN. In stark contrast, over two thirds of subjects chose NN. Interestingly, this game shows another behavioural feature not mentioned in GH. Given the strong incentive of Player 2 to choose NN, Player 1 could be expected to play the best reply $B$. This is, however, not the case for subjects in GH's experiment.

We claim that these results can be explained by ambiguity and are compatible with the estimated values of $\alpha$ and $\delta$. For player 2, strategy NN gives a certain pay-off of 30, even with ambiguity. Pessimistic responses to ambiguity can motivate him to choose NN, since all the

\footnotetext{
13 The name comes from Kreps (1995) who discusses the possibility that the level of payoffs, rather than their relative values, may affect players' behavior. The payoffs have been modified to allow the game to be run experimentally. These modifications do not affect the set of equilibria.
} 
other strategies can potentially yield a negative pay-off. Suppose that he has an ambiguous belief that player 1 will play $s_{1}$, where $s_{1}$ can either take the values $T$ or $B$, then the Choquet expected utility of his other strategies is given by: ${ }^{14}$

$$
\begin{aligned}
V_{2}(L) & \leqslant \delta \cdot[\alpha \cdot 50-(1-\alpha) \cdot 250]+(1-\delta) \cdot \max \left\{u_{2}(T, L), u_{2}(B, L)\right\} \\
& =50-\delta \cdot(1-\alpha) \cdot 300 \leqslant 30 \\
V_{2}(M) & \leqslant \delta[\alpha \cdot 45-(1-\alpha) \cdot 100]+(1-\delta) \cdot \max \left\{u_{2}(T, M), u_{2}(B, M)\right\} \\
& =45-\delta(1-\alpha) \cdot 145 \leqslant 30 \\
V_{2}(R) & \leqslant \delta \cdot[\alpha \cdot 40-(1-\alpha) \cdot 250]+(1-\delta) \cdot \max \left\{u_{2}(T, R), u_{2}(B, R)\right\} \\
& =40-\delta \cdot(1-\alpha) \cdot 290 \leqslant 30
\end{aligned}
$$

provided $\delta(1-\alpha) \geqslant \max \left\{\frac{50-30}{300}, \frac{45-30}{145}, \frac{40-30}{290}\right\}=\frac{3}{29}=0.103$. From which it follows that NN is a best response. If $\alpha$ and $\delta$ lie in the $\mathrm{KW}$-range then $0.16 \leqslant \delta(1-\alpha) \leqslant 0.37$. Hence in EUA, Player 2 will choose NN.

The observed behaviour of more than two thirds of Player 1's choosing $T$, can be obtained as an equilibrium under ambiguity, $\pi_{1}^{*}(T)=\pi_{2}^{*}(\mathrm{NN})=1$, but never as a NE. Assuming 2 is believed to play NN, the CEU value of pay-offs for Player 1 are:

$$
\begin{gathered}
V_{1}\left(s_{1}, \mathrm{NN}\right)=\delta \cdot\left[\alpha \cdot \max _{s_{2} \in S_{2}} u_{1}\left(s_{1}, s_{2}\right)+(1-\alpha) \cdot \min _{s_{2} \in S_{2}} u_{1}\left(s_{1}, s_{2}\right)\right]+(1-\delta) \cdot p_{1}\left(s_{1}, \mathrm{NN}\right) \\
=\left\{\begin{array}{lll}
\delta \cdot \alpha \cdot 200+(1-\delta) \cdot 10) & \text { for } s_{1}=T, \\
\delta \cdot \alpha \cdot 50+(1-\delta) \cdot 30 & \text { for } \quad s_{1}=B .
\end{array}\right.
\end{gathered}
$$

Thus $T$, is preferred to $B$ if and only if $150 \delta \alpha-(1-\delta) 20 \geqslant 0 \Longleftrightarrow \frac{\delta \alpha}{1-\delta} \geqslant \frac{2}{15}=0.13$. This inequality is satisfied for all $\alpha, \delta$ in the KW-range. Hence, with the experimentally observed parameter values for $\alpha$ and $\delta,\langle T, \mathrm{NN}\rangle$ are equilibrium strategies under ambiguity.

In Game $\mathrm{A}$ the deviation from Nash equilibrium arises because $\frac{2}{3}$ of the subjects play the strategy NN which is not part of Nash equilibrium. A possible explanation of this is Loss Aversion, see Kahneman, Knetsch \& Thaler (1991). This refers to the fact that individuals avoid taking actions which potentially could result in losing money. Loss aversion is in addition to conventional risk aversion, which can arise even when all pay-offs are positive. Note that NN

14 For convenience we are suppressing the arguments $\alpha, \delta$ and $\pi$. 
is the only strategy for player 2 which does not potentially lead to a negative pay-off. Hence Loss Aversion could be a reason why $68 \%$ of subjects choose NN in Game $A$.

Game $B$, is similar to Game $A$ except that 300 has been added to all pay-offs. This change does not affect the set of Nash equilibria nor does it affect the set of EUA.

Game B

Player 2

\begin{tabular}{|c|c|c|c|c|c|}
\hline \multirow{3}{*}{ Player } & & $(24 \%)$ & $(12 \%)$ & $(64 \%)$ & $(0 \%)$ \\
\hline & $(84 \%)$ & 500,350 & 300,345 & 310,330 & 320,50 \\
\hline & $(16 \%)$ & 300,50 & 310,200 & 330,330 & 350,340 \\
\hline
\end{tabular}

No strategy in Game B can yield losses. (Assuming that 0 is the reference point from which subjects measure gains/losses.) If significantly less players had played NN in Game B than in Game A, this would have been evidence that play of NN in the Game A was due to loss aversion. In fact adding the constant had little effect on the behaviour of player 2. This suggests that ambiguity-aversion is a more likely explanation for playing NN.

The "Treasure" treatment of the Kreps game is as follows.

Game C

Player 2

\begin{tabular}{|c|c|c|c|c|c|}
\hline \multirow{3}{*}{ Player 1} & & $L \quad(0 \%)$ & $(0 \%)$ & NN $\quad(16 \%)$ & $(84 \%)$ \\
\hline & $(4 \%)$ & 200,50 & 0,45 & 10,30 & $20,-250$ \\
\hline & $(96 \%)$ & $0,-250$ & $10,-100$ & 30,30 & 350,400 \\
\hline
\end{tabular}

The pay-offs from the strategy combination $\langle B, R\rangle$ have been substantially increased. This does not affect the set of Nash equilibria. It does vastly increase the number of players using the Nash equilibrium strategies $B$ and $R$.

It is easy to show that this result is also compatible with EUA. Consider first player 1. Suppose that she believes that player 2 will play $R$, then her (Choquet) expected utility from her two strategies are $V_{1}(T)=\delta \alpha 200-\delta(1-\alpha) 250-(1-\delta) 250$ and $V_{1}(B)=\delta \alpha 350+(1-\delta) 350$. It can be seen that $B$ will be preferred to $T$ for and $\alpha$ and $\delta, 0 \leqslant \alpha \leqslant 1,0 \leqslant \delta \leqslant 1$. Now suppose that player 2 believes that 1 will play $B$. Then his Choquet expected utility from his strategies is:

$$
\begin{aligned}
& V_{2}(L)=\delta \alpha 50-\delta(1-\alpha) 250-(1-\delta) 250 \\
& V_{2}(M)=\delta \alpha 45-\delta(1-\alpha) 100-(1-\delta) 100 \\
& V_{2}(\mathrm{NN})=30
\end{aligned}
$$




$$
V_{2}(B)=\delta \alpha 400-\delta(1-\alpha) 250+(1-\delta) 400 .
$$

First note that $B$ will be preferred to $L$ and $M$ for any $\alpha, \delta$. For $B$ to be preferred to NN we require: $\delta \alpha 40-\delta(1-\alpha) 25+(1-\delta) 40 \geqslant 3 \Leftrightarrow 37 \geqslant \delta(1-\alpha) 65 \Leftrightarrow 0.57=\frac{37}{65} \geqslant \delta(1-\alpha)$. All values of $\alpha, \delta$ with in the KW-range are compatible with this inequality and hence $\langle B, R\rangle$ is an equilibrium under ambiguity of Game $\mathrm{C}$.

\subsection{The Traveller's Dilemma}

In the Traveller's Dilemma, each player makes a claim $n_{i}$ for a payment between 180 and 300 cents, i.e., $n_{i} \in S:=\{180,181,182, \ldots, 298,299,300\} .{ }^{15}$ Given two claims $\left(n_{1}, n_{2}\right)$, both players obtain the minimum $\min \left\{n_{1}, n_{2}\right\}$, but, if the claims are not equal, the player with the higher claim pays $R>1$ to the other, yielding the payoff function:

$$
u_{i}\left(n_{1}, n_{2}\right)=\min \left\{n_{1}, n_{2}\right\}+R \cdot \operatorname{sign}\left(n_{j}-n_{i}\right),
$$

with $i, j \in\{1,2\}$ and $i \neq j$.

It is easy to see that for $R>1$ each player has an incentive to undercut the opponent's claim by one unit. The following diagram shows the best-reply of Player 1 . Hence, for any $R>1$, claiming the minimum amount, $\left(n_{1}^{*}, n_{2}^{*}\right)=(180,180)$, is the unique NE. In fact, $n_{i}^{*}=180$ is the only rationalisable strategy for each player, since it is the only strategy which cannot be undercut by the opponent.

GH show, however, that the experimental results, depend on $R$. For large $R$, players claim 180 , or close to this amount, as predicted by the NE. For $R=180$, almost 80 percent of the subjects chose $n_{i} \leqslant 185$. In contrast to the NE predictions, for small $R$, players make claims close to 300, i.e., for $R=5$, almost 80 percent of the players chose $n \geqslant 295$.

The evidence can be explained by ambiguity as follows. In the Traveller's Dilemma, pay-offs are high if players coordinate on a high claim. As a result there are two possible best responses to an action by one's opponent. Either one can undercut by one unit or alternatively one can choose 299 , which yields the highest coordination gain and maintains at least the chance to avoid the penalty. For $R=180$ however, the penalty for being the highest bidder is extreme,

15 The story which motivates the game can be found in Basu (1994), where this game was introduced. 


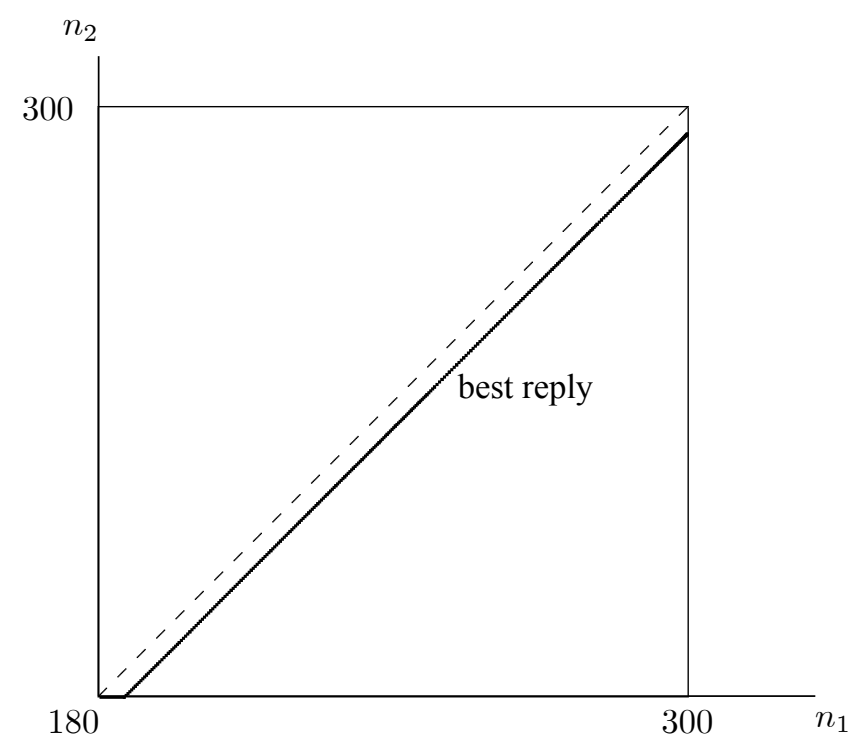

Figure 4. Best response of Player 1 without ambiguity

wiping out any possible gain from coordination. Hence, even a small amount of pessimism in response to ambiguity will deter players from making a high claim and the only possible equilibrium is where both claim 180 .

In contrast, for $R=5$, the penalty is so low that a little ambiguity and optimism, $\frac{\alpha \delta}{1-\delta} \geqslant 0.1$, suffices to make it worthwhile to claim 299. Figure 5 illustrates the equilibrium best-reply correspondence. There is a mixed equilibrium with two best responses 299 and $\bar{n}$. For example, if $\alpha=0.4$ and $\delta=0.6$, the ambiguous beliefs that one's opponent would choose $[\bar{n}]=285$ would be 0.18 and the belief for 299 would equal 0.82 . The observation, that 80 percent of subjects chose a claim higher than 295, seems to be not obviously incompatible with EUA for these values of $\alpha$ and $\delta$. This analysis is summarised in the following proposition.

Proposition 3.1 Suppose players's beliefs are given by a neo-additive capacity with parameters $\alpha, \delta$ in the $K W$-range.

1. For $R=180$, in the unique symmetric EUA both players have beliefs:

$$
\pi^{*}(180)=1 \text {. }
$$

In response, both players choose $n_{1}^{*}=n_{2}^{*}=180$.

2. For $R=5$, in the unique symmetric EUA is a mixed equilibrium in which each player has 


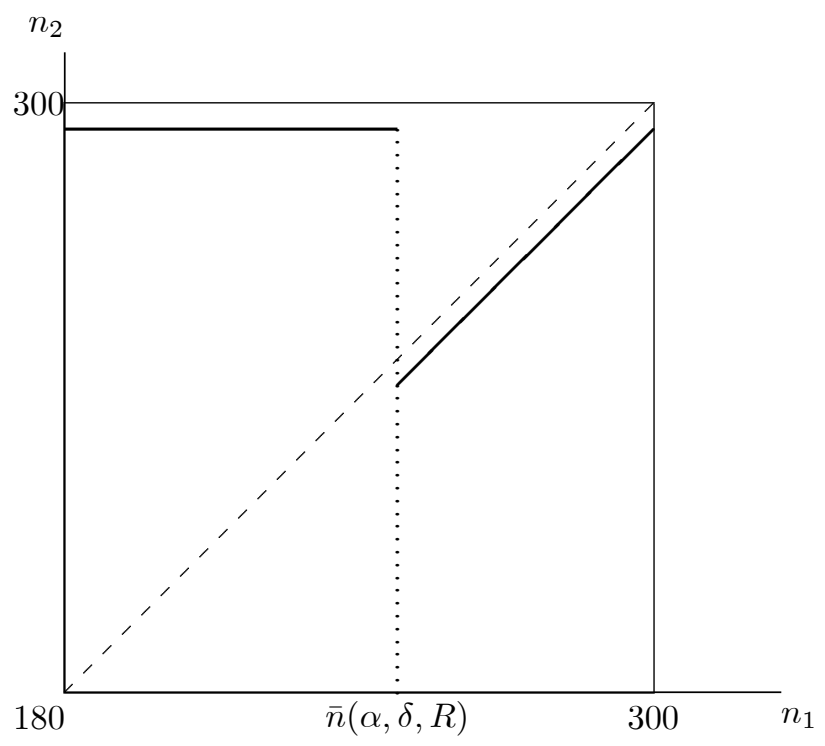

Figure 5. Best reply of Player 1 with ambiguity

two best responses, $[\bar{n}]$ and 299 where ${ }^{16}$

$$
\bar{n}(\alpha, \delta, R):=\left(300-\frac{1-\delta}{\alpha \delta}(2 R-1)\right) .
$$

The table below gives the values of $[\bar{n}]$ for $R=5$ and parameter values in the KW-range.

\begin{tabular}{|c|c|c|c|}
\hline \multicolumn{4}{|c|}{$\alpha$} \\
\hline & 0.4 & 0,5 & 0.62 \\
\hline 0.41 & 268 & 274 & 280 \\
\hline 0.52 & 279 & 283 & 286 \\
\hline 0.61 & 285 & 288 & 291 \\
\hline
\end{tabular}

\subsection{Matching Pennies}

In experiments on the Matching Pennies game, GH discover that subjects tend to conform with NE predictions if the game is symmetric, but deviate systematically if the pay-offs are asymmetric. They study the following two versions of matching pennies. ${ }^{17}$ The ratios to the left of the strategies indicate the unique NE mixed strategies and the bold numbers to the right of the strategies show the percentage of subjects choosing the respective strategy in the experiments.

16 As usual $[y]$ denotes the largest integer smaller than $y$.

17 GH also consider a third version of matching pennies. The impact of ambiguity on this game can be analysed in a similar way. 
Game D

Player 2

\begin{tabular}{|c|c|c|c|c|}
\hline \multirow{3}{*}{ Player 1} & & & $(48 \%)$ & $(52 \%)$ \\
\hline & 0.5 & $(48 \%)$ & 80,40 & 40,80 \\
\hline & 0.5 & $(52 \%)$ & 40,80 & 80,40 \\
\hline
\end{tabular}

Game E

Player 2

\begin{tabular}{|c|c|c|c|c|}
\hline \multirow{3}{*}{ Player 1} & & & $(16 \%)$ & $(84 \%)$ \\
\hline & 0.5 & $T \quad(96 \%)$ & $\mathbf{3 2 0}, 40$ & 40,80 \\
\hline & 0 . & $(4 \%)$ & 40,80 & 80,40 \\
\hline
\end{tabular}

The games differ only in the payoff of Player 1 for $\langle T, L\rangle$, which is indicated by a bold-face number. In mixed-strategy NE, the probabilities which a given player uses to randomise, are chosen to make his/her opponent indifferent between all of his/her equilibrium strategies. Thus NE predicts that a change in player 1's payoff will leave her own behaviour unchanged, while causing a change in the behaviour of player 2 .

Actual play reveals a quite different pattern. While the relative frequency of strategy choices in Game $D$ correspond to the NE prediction, they deviate dramatically from the predictions in the asymmetric game. In Game $E$, Player 1's choose almost exclusively strategy $T$, the payoff of which has been increased. As a result they make their behaviour predictable, which is exploited by the subjects in the role of Player 2. It is surprising that Player 1 does not appear to foresee this shift in the behaviour of her opponent. It appears as if Player 2 understands the change in Player 1's incentives better than she does herself. One interpretation of Player 1's behaviour may be a shift in decision weights to extremely attractive low-probability events.

Ambiguity makes little difference to game $D$. Symmetry implies that the only equilibrium is where each player believes that his/her opponent is equally likely to use either strategy. In game $E$, optimistic responses to ambiguity cause player 1 to overweight unlikely events which yield the high payoff 320. This causes her to choose strategy $T$ almost exclusively. From Player 2's point of view, the two strategies are symmetric. However 1 has a bias in favour of $T$. Hence $R$ is a best response for 2. Thus for the parameter values we find in Kilka and Weber's experiments, there is an equilibrium with ambiguity where the equilibrium strategy combination is $\langle T, L\rangle$. (For details see the appendix.) There is no NE which describes such behaviour. There is a 
unique NE, where Player 2 plays $\pi(L)=\frac{1}{8}$ and Player 1 plays $\pi(T)=\frac{1}{2}$. Such randomisations are incompatible with the observed choices.

This discussion is summarised in the following proposition, which is proved in the appendix.

Proposition 3.2 Suppose players's beliefs are given by a neo-additive capacity with parameters $\alpha, \delta$ in the $K W$-range.

1. In game $D$ there is a unique EUA where each player is equally likely to use either strategy i.e. $\nu_{1}(T)=\nu_{1}(B)$ and $\nu_{2}(L)=\nu_{2}(R)$.

2. In game E there is a unique EUA in which $T$ is the best response of player 1 and $R$ is the best response of player 2.

\subsection{A Coordination Game with a Secure Option}

GH study two coordination games, which have been modified by giving Player 2 an extra secure option.

\begin{tabular}{cc|c|c|c|} 
Game F & \multicolumn{4}{c}{ Player 2 } \\
Player 1 & & $L(?)$ & $H(84)$ & $S(?)$ \\
\cline { 2 - 5 } & $L(4)$ & 90,90 & 0,0 & $\mathbf{0}, 40$ \\
\cline { 2 - 5 } Game G & $H(96)$ & 0,0 & 180,180 & 0,40 \\
\cline { 2 - 5 } Player 1 & \multicolumn{5}{|c}{ Player 2 } \\
& \multicolumn{1}{|c|}{$L(?)$} & $H(76)$ & $S(?)$ \\
\cline { 2 - 5 } & $H(64)$ & 90,90 & 0,0 & $\mathbf{4 0 0}, 40$ \\
\cline { 2 - 5 } & & 0,0 & 180,180 & 0,40 \\
\hline
\end{tabular}

Both of these games have two NEs, $\langle L, L\rangle$ and $\langle H, H\rangle$. The data suggests that in Game $F$ subjects are nearly all playing the $\langle H, H\rangle$ equilibrium. In game $G$ the majority of the subjects are still playing the $\langle H, H\rangle$ equilibrium, while a significant minority of players have switched to other strategies. ${ }^{18}$

For this experiment we are not able to make a precise prediction since both games have multiple equilibria with and without ambiguity. However we shall show that the results are not incompatible with EUA. The following proposition shows that while in Game $F,\langle H, H\rangle$ is an equilibrium for all parameters values in the KW-range, in Game $G$ this equilibrium only exists for some parameters in this range. Thus in moving from Game $F$ to Game $G$ one would expect some subjects to switch from $H$ to another strategy. It is not possible to predict how many 18 GH do not report whether player 2 switches to $L$ or $S$. 
subjects will switch without more details of the distribution of $\alpha$ and $\delta$. Unless the distributions of the parameters are concentrated at the upper ends of their ranges, only a minority of subjects would switch. Thus the theoretical prediction agrees with the experimental result at least qualitatively.

Proposition 3.3 For the coordination game with a secure option:

1. In game $F$ both $\langle H, H\rangle$ and $\langle L, L\rangle$ are EUA for all parameters in the $K W$-range.

2. In game $G$,

a. $\langle H, H\rangle$ is an EUA for $\alpha, \delta$ in the $K W$-range provided $0.82 \geqslant \frac{\delta \alpha}{1-\delta}$.

b. $\langle L, L\rangle$ is an EUA for all parameters in the $K W$-range.

Whether the $\langle H, H\rangle$ equilibrium exists in game $\mathrm{G}$ depends on the parameter $\eta=\frac{\delta \alpha}{1-\delta}$. KW's evidence shows that $0.28 \leqslant \eta \leqslant 0.97$. For illustrative purposes assume that $\eta$ is uniformly distributed on this range. Then for $21 \%$ of subjects, the $\langle H, H\rangle$ equilibrium will not exist in Game $G$. This is qualitatively similar to the experimental results, where $36 \%$ play $L$ in Game G. The discrepancy between $21 \%$ and $36 \%$ could be explained either because $\eta$ is not uniformly distributed or because subjects perceive co-ordination games to be more ambiguous than KW's single person decisions, (i.e. $\delta$ is larger than in the KW experiment). It is plausible that players might perceive coordination games to be more ambiguous. The presence of multiple equilibria means that even if one believes one's opponent will play an equilibrium strategy it is not clear which one. Moreover there is no natural way to assign probabilities to the different equilibria. If in addition it is not clear that one's opponents will play an equilibrium strategy this increases the ambiguity still further.

\subsection{A Minimum-Effort Coordination Game}

In the minimum effort coordination game (also know as the weakest link model of public goods, see Cornes \& Sandler (1996)) two players have to choose effort levels from the set $E=\{110, \ldots, 170\}$ at a marginal cost of $c<1$ yielding pay-offs

$$
u_{i}\left(e_{1}, e_{2}\right):=\min \left\{e_{1}, e_{2}\right\}-c \cdot e_{i}
$$


for $i=1,2$. GH played this experiment with the marginal cost parameters 0.1 and 0.9 and observed the following distributions of play: ${ }^{19}$

\begin{tabular}{l|c|c|c|c|c|c|} 
Game H & $e=115$ & $e=125$ & $e=135$ & $e=145$ & $e=155$ & $e=165$ \\
\hline$c=0.1$ & 0.1 & 0.02 & 0.1 & 0.1 & 0.08 & 0.6 \\
\hline$c=0.9$ & 0.5 & 0.18 & 0.05 & 0.07 & 0.05 & 0.15 \\
\hline
\end{tabular}

The observations show a clear concentration of play on high effort levels in the case of low costs, $c=0.1$, and on the low ones for high costs, $c=0.9$. Coordinating on any of the six possible effort levels is a Nash equilibrium for either possible value of costs i.e., the set of NE's is $\left\{\left(e_{1}^{*}, e_{2}^{*}\right) \in E^{2} \mid e_{1}^{*}=e_{2}^{*}\right\}$. Thus Nash equilibrium is unable to explain why an increase in the cost parameter changes behaviour. Since the experiments were one-shot games and there were many possible equilibria, coordination is not very likely.

We shall argue that such observations can be explained by ambiguity. In this game, the best outcome is that your opponent plays the highest possible strategy. Suppose there is an equilibrium with ambiguity in which both players coordinate on an effort level other than the highest. If Player 1 increases her effort by one unit, the perceived marginal benefit is $\delta \alpha$, which is the weight on the highest outcome. The marginal cost of increasing effort is $c$. Thus if $\delta \alpha>c$ it is in her interest to increase her contribution. Player 2 will think similarly. Hence under the assumption $\delta \alpha>c$ the only possible equilibrium is where both players make the highest contribution.

Suppose there is an equilibrium with ambiguity in which both players use an effort level other than the lowest (i.e. 115). If Player 1 decreases her contribution by one unit the perceived marginal reduction in benefit is $\delta \alpha+(1-\delta)$. The marginal cost saving is $c$. Thus if $c>$ $\delta \alpha+(1-\delta)$ it is worth decreasing effort, which implies that the only possible equilibrium is where both players coordinate on the lowest effort level.

If $\alpha$ and $\delta$ lie in the KW-range we have $0.38 \geqslant \delta \alpha \geqslant 0.16$, which implies $\delta \cdot \alpha-c>0$ for $c=0.1$. Similarly Kilka and Weber's experiment implies $0.85 \geqslant \delta \alpha+(1-\delta) \geqslant 0.64$ and hence $c>[\delta \cdot \alpha+(1-\delta)]$ for $c=0.9$. For marginal costs of 0.1 , equilibrium with ambiguity predicts

$1 \overline{9}$ Note that GH have grouped the data for ten successive integers. 
that players would try to coordinate on the highest effort level, while for $c=0.9$ they should coordinate on the lowest effort level. The observed behaviour seems to correspond reasonably well with this prediction.

\section{COMPETING EXPLANATIONS}

For economic theory, the notion of a Nash equilibrium is attractive. If the pay-offs of players are common knowledge, a Nash equilibrium identifies strategy combinations which leave no incentives for individual players to change their behaviour as long as the opponents' follow their equilibrium strategy. Thus, it combines two key ideas:

(i) Players choose the best strategy given their beliefs about the behaviour of the opponents and

(ii) Beliefs about the behaviour of the opponents are correct.

In order to infer their opponents' behaviour in one-shot games, however, players need to know the incentives of these opponents. Whether the pay-offs of a player reflect the incentives of this player correctly is however questionable. Attitudes towards risk and ambiguity may matter, just as social attitudes like preferences for fairness, altruism or spite may affect behaviour.

The regularities of behaviour recorded in GH's experiments challenge the idea that the interaction of subjects in a one-shot game can be appropriately described by Nash-equilibrium. Yet, as the treasure treatments show, NE does seem to work well for some payoff constellations.

There are several responses to the challenge posed by the experimental results reported in GH. One may take into account additional aspects of preferences, one may relax the assumption that players maximise an objective function, or one may give up the idea of consistency between beliefs and actual behaviour. Examples of the first approach include the fairness-based payoff transformations in the spirit of Fehr \& Schmidt (1999) and Rabin (1993) and the EUA approach suggested in this paper. The Quantal Response Equilibrium (QRE) proposed by McKelvey \& Palfrey (1995) provides an example for the second type of response. QRE assumes that players play mixed strategies which assign probabilities to the pure strategies based on the relative ex- 
pected payoff obtained with them ${ }^{20}$. McKelvey \& Palfrey (1995) show that QRE can be viewed as a Bayesian equilibrium of a game of imperfect information with payoff uncertainty. In contrast to models which explicitly assume a bias in the payoff evaluation QRE does not suggest a reason for the particular error structure assumed. The third group of responses is represented by the Cognitive Hierarchy Model (CHM) of Camerer, Ho \& Chong (2004). Building on the k-level optimality model proposed by Stahl \& Wilson (1995) this approach abandons the notion of equilibrium. It assumes a distribution of player types characterised by different levels of rationality. These different levels of rationality remain unrelated to the actual behaviour of players.

For the asymmetric Matching-Pennies game, Boylan \& Grant (2006) consider fairness-based payoff transformations in the spirit of Fehr \& Schmidt (1999) and Rabin (1993). They show, however, that such preferences do not predict the observed behaviour. In contrast, they find that the $Q R E$ can explain the experimental data of Goeree \& Holt (2001). To the best of our knowledge there exists no study comparing these approaches. It appears however likely that all these approaches will explain the observed data better than NE. They all add more parameters to the model: EUA adds parameters for ambiguity and ambiguity attitude, $Q R E$ adds a sensitivity parameter, and $C H M$ allows for arbitrary levels of rationality. If these parameters can be adjusted freely, it is not surprising that a better fit to the data can be achieved.

A better test requires constraints on these new parameters. In our opinion, this is the main advantage of the EUA. Ambiguity and ambiguity attitudes have been studied in large numbers of non-interactive decision-making experiments. From these studies we can obtain additional constraints for the parameters $\alpha$ and $\delta$. As we have shown in this paper, estimates of these parameters from the range obtained in many experiments seem to suffice to explain the observed behaviour in the games of GH. Ideally, one would want to assess these parameters from the participants of the game-theoretic experiments. For instance, one could run pretests in which subjects choices over ambiguous bets reveal their ambiguity attitude, before they interact with

20 Since the expected payoffs from a player's pure strategy depend on the mixed strategies chosen by the op-
ponents, QRE has to solve a fixed point problem in order to obtain consistency among the players' mixed strategies. 
other players in games. Neither $Q R E$ nor $C H M$ offer such possibilities because the parameters of "sensitivity" and "level of rationality" lack an interpretation outside the given game. They just measure the deviation from full rationality embodied in the Nash equilibrium concept.

All these approaches are more flexible in describing actual behaviour than NE, however we believe that $E U A$ may be given a more attractive interpretation. Ambiguity attitude, optimism and pessimism, can be viewed as personal characteristics, which we may take as given, like a player's preferences. Ambiguity, on the other hand, is more situation-dependent. In particular, one would predict that a one-shot game is by nature more ambiguous than later rounds of a repeated game. Hence, there are testable hypotheses regarding $E U A$ which have no counter-part in $Q R E$ and $C H M$. Moreover, there is substantial evidence on individual behaviour, which allows one to predict the attitude of a decision-maker towards ambiguity. Such evidence can help to restrict behaviour in $E U A$, which makes the theory more powerful. It is a particular strength of $E U A$ that it can explain the diverging behaviour in many games with the same set of ambiguity and optimism parameters. Indeed, a recent paper by Haile, Hortascu \& Kosenok (2003) shows that "without a priori distributional assumptions, a $Q R E$ can match any distribution of behaviour by each player in any normal form game". In contrast, the hypothesis that players view their opponents' actions as ambiguous, produces some quite precise comparative predictions, which could in principle be tested experimentally.

For economic analysis, it is desirable to have a model with parameters which one can interpret behaviourally and which include the "full rationality" of a Nash equilibrium as a special case. While Nash equilibrium can be obtained as a limiting case in all these models, a behavioural interpretation can be given only in the context of the fairness approach of Fehr \& Schmidt (1999) and the EUA. Since the parameters of $Q R E$ and $C H M$ are harder to interpret, it appears also more difficult to use these concepts in economic analysis.

\section{CONCLUSION}

In this paper we have shown that many of the treasures of game theory from GH can be 
explained as responses to ambiguity. We have shown that four of the five Treasures can be explained by the hypothesis that subjects have CEU preferences with parameters in the KWrange. In the coordination game with a secure option there are multiple equilibria with and without ambiguity. Thus it is not possible to make a point prediction. However the shift in behaviour between Games F and G appears, at least in qualitative terms to be compatible with our model of ambiguity.

We have only analysed those treasures based on normal form games. The other experiments concern dynamic games some of which also have incomplete information. To study the impact of ambiguity in these cases it would be necessary to develop new solution concepts for such games. This is beyond the scope of the present article. Nevertheless we believe that explanations based on ambiguity could be found for many of these games as well. For instance, the treasure from GH entitled 'Should you believe a threat that is not credible' is similar to the model of frivolous lawsuits in Eichberger \& Kelsey (2004).

The preferences we use have the effect of over weighting the best and worst outcomes. It is likely that ambiguity-aversion would cause other bad outcomes to be over weighted. Similarly optimism might have the effect that a number of good outcomes are over-weighted rather than just the best outcome. While this objection may have some merits in general, the games studied in this paper typically have salient best and worst outcomes. It does not seem implausible that over-weighting should be concentrated on these outcomes. In Eichberger \& Kelsey (2006) we show that much of our analysis can be extended to the more general case where a number of good and bad outcomes are over weighted.

\section{REFERENCES}

Abdellaoui, M. (2000). Parameter-free elicitation of utility and probability weighting functions, Management Science 46: 1497-1512.

Basu, K. (1994). The traveler's dilemma: Paradoxes of rationality in game theory, American Economic Review (Papers and Proceedings) 84: 391-395.

Boylan, R. T. \& Grant, S. (2006). Incorporating fairness in generalized games of matching pennies, working paper .

Camerer, C. F., Ho, T.-H. \& Chong, J.-K. (2004). A cognitive hierarchy model of games, Quaterly 
Journal of Economics pp. 861-898.

Camerer, C. \& Weber, M. (1992). Recent developments in modelling preferences: Uncertainty and ambiguity, Journal of Risk and Uncertainty 5: 325-370.

Chateauneuf, A., Eichberger, J. \& Grant, S. (2007). Choice under uncertainty with the best and worst in mind: NEO-additive capacities, Journal of Economic Theory 137: 538-567.

Cohen, M., Jaffray, J.-Y. \& Said, T. (1985). Individual behaviour under risk and uncertainty: An experimental study, Theory and Decision 18: 203-228.

Colman, A. \& Pulford, B. (2007). Ambiguous games: Evidence for strategic ambiguity aversion, Quarterly Journal of Experimental Psychology 60: 1083-1100.

Cornes, R. \& Sandler, T. (1996). The Theory of Externalities, Public Goods and Club Goods, 2nd edn, Cambridge University Press, Cambridge, UK.

Dow, J. \& Werlang, S. R. C. (1994). Nash equilibrium under uncertainty: Breaking down backward induction, Journal of Economic Theory 64: 305-324.

Eichberger, J. \& Kelsey, D. (2000). Non-Additive beliefs and strategic equilibria, Games and Economic Behavior 30: 183-215.

Eichberger, J. \& Kelsey, D. (2004). Sequential two-player games with ambiguity, International Economic Review 45: 1229-1261.

Eichberger, J. \& Kelsey, D. (2006). Optimism and pessimism in games, Working Paper .

Eichberger, J., Kelsey, D. \& Schipper, B. (2008a). Ambiguity and social interaction, Oxford Economic Papers forthcoming.

Eichberger, J., Kelsey, D. \& Schipper, B. (2008b). Granny versus game theorist: Ambiguity in experimental games, Theory and Decision 64: 333-362.

Ellsberg, D. (1961). Risk, ambiguity, and the savage axioms, Quarterly Journal of Economics 75: 643-669.

Fehr, E. \& Schmidt, K. M. (1999). A theory of fairness, competition and cooperation, Quarterly Journal of Economics 114(3): 817 - 868.

Gilboa, I. \& Schmeidler, D. (1989). Maxmin expected utility with a non-unique prior, Journal of Mathematical Economics 18: 141-153.

Goeree, J. K. \& Holt, C. A. (2001). Ten little treasures of game theory and ten intuitive contradictions, American Economic Review 91: 1402-1422.

Gonzalez, R. \& Wu, G. (1999). On the shape of the probability weighting function, Cognitive Psychology 38: 129-166.

Haile, P. A., Hortascu, A. \& Kosenok, G. (2003). On the empirical content of quantal response equilibrium, Cowles Foundation Discussion Paper 1432.

Kahneman, D., Knetsch, J. \& Thaler, R. (1991). Anomalies: The endowment effect, loss aversion and status quo bias, Journal of Economic Perspectives 5: 193-206.

Kilka, M. \& Weber, M. (2001). What determines the shape of the probability weighting function under uncertainty?, Management Science 47: 1712-1726.

Kreps, D. (1995). Nash equilibrium, in J. Eatwell, M. Milgate \& T. Palfrey (eds), The New Palgrave: Game Theory, Norton, pp. 176-177.

Lo, K. C. (1996). Equilibrium in beliefs under uncertainty, Journal of Economic Theory 71: 443484. 
Marinacci, M. (2000). Ambiguous games, Games and Economic Behavior 31: 191-219.

McKelvey, R. D. \& Palfrey, T. R. (1995). Quantal response equilibria for normal form games, Games and Economic Behavior 10: 6-38.

Rabin, M. (1993). Incorporating fairness into game theory and economics, American Economic Review 83(5): 1281 - 1302.

Ryan, M. J. (1997). CEU preferences and game theoretic equilibrium, The University of Auckland, working paper series no. 167.

Schmeidler, D. (1989). Subjective probability and expected utility without additivity, Econometrica 57: $571-587$.

Stahl, D. O. \& Wilson, P. (1995). On players' models of other players: Theory and experimental evidence, Games and Economic Behavior 10: 213 - 254.

Tversky, A. \& Wakker, P. (1995). Risk attitudes and decision weights, Econometrica 63: 1255-1280.

Wakker, P. (2001). Testing and characterizing properties of nonadditive measures through violations of the sure thing principle, Econometrica 69: 1039-1060. 


\section{APPENDIX}

The appendices provide details of the model and proofs of the claims made in the corresponding section of the text.

\section{Appendix A. The Traveller's Dilemma}

Consider Player 1. Suppose she holds beliefs which are represented by a neo-additive capacity: $\nu(A \mid \alpha, \delta, \pi)=\alpha \delta+(1-\delta) \pi(A)$. Given these beliefs, Player 1's Choquet expected utility from the choice of $n_{1}$ is

$$
\begin{aligned}
V_{1}\left(n_{1} ; \alpha, \delta, \pi\right)= & \delta\left[\alpha \max _{n_{2} \in S} u_{1}\left(n_{1}, n_{2}\right)+(1-\alpha) \min _{n_{2} \in S} u_{1}\left(n_{1}, n_{2}\right)\right] \\
& +(1-\delta) \cdot \sum_{n_{2} \in S} u_{1}\left(n_{1}, n_{2}\right) \cdot \pi\left(n_{2}\right) .
\end{aligned}
$$

Lemma A.1 Suppose Player 1 's beliefs are given by a neo-additive capacity $\nu\left(\cdot \mid \alpha, \delta, \pi^{n_{2}}\right)$. If $\alpha$ and $\delta$ lie in the $K W$-range then the best-reply correspondence is

$$
R_{1}\left(\nu\left(\cdot \mid \alpha, \delta, n_{2}\right)\right)= \begin{cases}299 & \text { for } n_{2}<\bar{n}(\alpha, \delta, R) \\ n_{2}-1 & \text { otherwise, }\end{cases}
$$

with

$$
\bar{n}(\alpha, \delta, R):=300-\frac{1-\delta}{\alpha \delta}(2 R-1)
$$

Proof. First note that $R>1, n_{1}=299$ weakly dominates $n_{1}=300$, moreover, for $\alpha, \delta>0$, $n_{1}=300$ is strictly dominated. Since the highest pay-off for $n_{1}=299$ is greater than that for $n_{1}=300$, and under our assumptions on $\alpha$ and $\delta$, the highest payoff gets positive weight in the Choquet integral. Thus we may eliminate the possibility that either player plays strategy 300 .

Consider $n_{2}=180$. The CEU of a pure strategy $n_{1}$ can be computed as. ${ }^{21}$

$$
\begin{aligned}
& V_{1}\left(n_{1} ; \alpha, \delta, \pi^{180}\right):=\int u_{1}\left(n_{1}, \cdot\right) d \nu_{1}\left(\cdot \mid \alpha, \delta, \pi^{180}\right) \\
= & \delta\left[\alpha \max _{n_{2} \in S} u_{1}\left(n_{1}, n_{2}\right)+(1-\alpha) \min _{n_{2} \in S} u_{1}\left(n_{1}, n_{2}\right)\right]+(1-\delta) \cdot u_{1}\left(n_{1}, 180\right)
\end{aligned}
$$

21 Here $\pi^{n_{2}}$ denotes the Dirac measure with support $n_{2}$. 


$$
= \begin{cases}\delta[\alpha(180+R)+(1-\alpha) 180]+(1-\delta) \cdot 180 & \text { for } \quad n_{1}=180, \\ \delta\left[\alpha\left(n_{1}+R\right)+(1-\alpha)(180-R)\right]+(1-\delta) \cdot[180-R] & \text { for } \quad 180<n_{1}<300 .\end{cases}
$$

Consider next $n_{2} \in(180,300)$. The CEU of a pure strategy combination $\left(n_{1}, n_{2}\right)$ is,

$$
\begin{gathered}
V_{1}\left(n_{1} ; \alpha, \delta, \pi^{n_{2}}\right):=\int u_{1}\left(n_{1}, \cdot\right) d \nu_{1}\left(\cdot \mid \alpha, \delta, \pi^{n_{2}}\right) \\
= \begin{cases}\delta[\alpha(180+R)+(1-\alpha) 180]+(1-\delta) \cdot[180+R] & \text { for } \quad n_{1}=180 ; \\
\delta\left[\alpha\left(n_{1}+R\right)+(1-\alpha)(180-R)\right]+(1-\delta) \cdot\left[n_{1}+R\right] & \text { for } \quad 180<n_{1}<n_{2} ; \\
\delta\left[\alpha\left(n_{1}+R\right)+(1-\alpha)(180-R)\right]+(1-\delta) \cdot n_{1} & \text { for } \quad n_{1}=n_{2} ; \\
\delta\left[\alpha\left(n_{1}+R\right)+(1-\alpha)(180-R)\right]+(1-\delta) \cdot\left[n_{2}-R\right] & \text { for } \quad n_{2}<n_{1}<300 .\end{cases}
\end{gathered}
$$

(ii) For $n_{2}=180, V_{1}\left(n_{1} ; \alpha, \delta, \pi^{180}\right)$ is strictly increasing in $n_{1}$ for $n_{1}>180$. Hence,

$$
\begin{aligned}
V_{1}\left(299 ; \alpha, \delta, \pi^{180}\right)-V_{1}\left(180 ; \alpha, \delta, \pi^{180}\right) & =\alpha \delta(299-180)-(1-\alpha \delta) R \\
& =119 \alpha \delta-(1-\alpha \delta) R
\end{aligned}
$$

Thus

$$
R_{1}(\nu(\cdot \mid \alpha, \delta, 180))= \begin{cases}299 & \text { for } \quad \alpha \delta>\frac{R}{119+R} \\ 180 & \text { otherwise. }\end{cases}
$$

Notice, for $R=5, \frac{R}{119+R}=\frac{5}{124} \approx 0.041 \leqslant 0.4 \cdot 0.4$.1. Hence, $R_{1}(\nu(\cdot \mid \alpha, \delta, 180))=299$. For $R=180$, we have $\frac{R}{119+R}=\frac{180}{299} \approx 0.6>0.61 \cdot 0.62$ and $R_{1}(\nu(\cdot \mid \alpha, \delta, 180))=180$.

(iii) Consider now $n_{2} \in(180,300)$.

For $n_{1} \in\left(180, n_{2}\right) \cup\left(n_{2}, 300\right)$ the CEU value is strictly increasing in $n_{1}$. Hence, only $n_{1}=180, n_{1}=n_{2}-1, n_{1}=n_{2}$, or $n_{1}=299$ can be best responses.

(a) Comparing $n_{1}=n_{2}-1$ and $n_{1}=n_{2}$, we observe that:

$$
\begin{aligned}
& V_{1}\left(n_{2} ; \alpha, \delta, \pi^{n_{2}}\right)-V_{1}\left(n_{2}-1 ; \alpha, \delta, \pi^{n_{2}}\right) \\
= & \left\{\delta\left[\alpha\left(n_{2}+R\right)+(1-\alpha)(180-R)\right]+(1-\delta) \cdot n_{2}\right\} \\
& -\left\{\delta\left[\alpha\left(n_{2}-1+R\right)+(1-\alpha)(180-R)\right]+(1-\delta) \cdot\left(n_{2}-1+R\right)\right\} \\
= & \delta \alpha+(1-\delta) \cdot(1-R)=\delta \alpha+\delta(R-1)-(R-1)<0
\end{aligned}
$$


holds, for $R>1+\alpha$. For $R=5$ and $R=180$, this condition is satisfied. Hence, $n_{1}=n_{2}$ cannot be a best reply.

(b) Comparing $n_{1}=180$ and $n_{1}=299$.

(b1) Suppose $181 \leqslant n_{2} \leqslant 298$, then we observe that $V_{1}\left(299 ; \alpha, \delta, \pi^{n_{2}}\right)-V_{1}\left(180 ; \alpha, \delta, \pi^{n_{2}}\right)=\left(\delta[\alpha(299+R)+(1-\alpha)(180-R)]+(1-\delta) \cdot\left[n_{2}-R\right]\right)$ $-(\delta[\alpha(180+R)+(1-\alpha) 180]+(1-\delta) \cdot[180+R])$ $=119 \delta \alpha+(1-\delta) \cdot\left(n_{2}-180-2 R\right) \gtreqless 0 \Leftrightarrow n_{2} \gtreqless 180+2 R-\frac{\delta \alpha}{1-\delta} 119$.

By the assumption $0.28 \leqslant \frac{\alpha \delta}{1-\delta} \leqslant 0.97$, we obtain for $R=5,180>180+2 \cdot 5-0.28 \cdot 119 \geqslant$ $180+2 R-\frac{\delta \alpha}{1-\delta} 119$. Hence, for $R=5, V_{1}\left(299 ; \alpha, \delta, \pi^{n_{2}}\right)>V_{1}\left(180 ; \alpha, \delta, \pi^{n_{2}}\right)$ for all $n_{2}>180$. Moreover, for $R=180$, we find that $180+2 R-\frac{\delta \alpha}{1-\delta} 119>180+2 \cdot 180-0.97 \cdot 119>300$. Thus, $V\left(180 ; \alpha, \delta, \pi^{n_{2}}\right)>V\left(299 ; \alpha, \delta, \pi^{n_{2}}\right)$ in this case.

(b2) For $n_{2}=299$,

$$
\begin{aligned}
& V_{1}\left(299 ; \alpha, \delta, \pi^{299}\right)-V_{1}\left(180 ; \alpha, \delta, \pi^{299}\right) \\
= & \{\delta[\alpha(299+R)+(1-\alpha)(180-R)]+(1-\delta) \cdot 299\} \\
& -\{\delta[\alpha(180+R)+(1-\alpha) 180]+(1-\delta) \cdot[180+R]\} \\
= & 119 \delta \alpha+(1-\delta) \cdot(119-R) \gtreqless 0 \Longleftrightarrow 119\left(1+\frac{\alpha \delta}{1-\delta}\right) \gtreqless R .
\end{aligned}
$$

For $R=5$, this condition is satisfied, hence, $n_{1}=299$ is the best reply to a belief concentrated on $n_{2}=299$. For $R=180,119\left(1+\frac{\alpha \delta}{1-\delta}\right) \leq 119(1+0.28)<180=R$. Hence, $V_{1}\left(299 ; \alpha, \delta, \pi^{299}\right)<V_{1}\left(180 ; \alpha, \delta, \pi^{299}\right)$.

(c) Comparing $n_{1}=n_{2}-1$ with $n_{1}=299$.

(c1) For $n_{2}=299$, we obtain

$$
\begin{aligned}
& V_{1}\left(298 ; \alpha, \delta, \pi^{299}\right)-V_{1}\left(299 ; \alpha, \delta, \pi^{299}\right) \\
= & \{\delta[\alpha(298+R)+(1-\alpha)(180-R)]+(1-\delta) \cdot(298+R)\} \\
& -\{\delta[\alpha(299+R)+(1-\alpha)(180-R)]+(1-\delta) \cdot 299\} \\
= & \delta \alpha(-1)+(1-\delta) \cdot(R-1) \gtreqless 0
\end{aligned}
$$


as $R \gtreqless 1+\frac{\alpha \delta}{1-\delta}$. From $\frac{\alpha \delta}{1-\delta} \leqslant 0.97$ we have $R>1+\frac{\alpha \delta}{1-\delta}$ for $R \geqslant 2$. Thus, $n_{1}=298$ is the best reply to 299 .

(c2) For $n_{2}<299$, we obtain

$$
\begin{aligned}
& V_{1}\left(n_{2}-1 ; \alpha, \delta, \pi^{n_{2}}\right)-V_{1}\left(299 ; \alpha, \delta, \pi^{n_{2}}\right) \\
= & \left\{\delta\left[\alpha\left(n_{2}-1+R\right)+(1-\alpha)(180-R)\right]+(1-\delta) \cdot\left(n_{2}-1+R\right)\right\} \\
& -\left\{\delta[\alpha(299+R)+(1-\alpha)(180-R)]+(1-\delta) \cdot\left(n_{2}-R\right)\right\} \\
= & \delta \alpha\left(n_{2}-300\right)+(1-\delta) \cdot(2 R-1),
\end{aligned}
$$

thus

$$
n_{2} \gtreqless 300-\frac{1-\delta}{\alpha \delta}(2 R-1)=: \bar{n}(\alpha, \delta, R) .
$$

Hence,

$$
R_{1}\left(\nu\left(\cdot \mid \alpha, \delta, n_{2}\right)\right)= \begin{cases}299 & \text { for } n_{2}<\bar{n}(\alpha, \delta, R) \\ n_{2}-1 & \text { otherwise. }\end{cases}
$$

For $R=180, \bar{n}(\alpha, \delta, R)<0$. More precisely, for the parameter values of $\alpha$ and $\delta$ it ranges between $300-\frac{1-\delta}{\alpha \delta}(2 R-1)=300-\frac{359}{0.28} \simeq-982$ and $300-\frac{1-\delta}{\alpha \delta}(2 R-1)=300-\frac{359}{0.97} \simeq-70$. Since $n_{2}>180, n_{1}=n_{2}-1$ is the best response.

Notice, for $R=5, \bar{n}(\alpha, \delta, R)$ can range between $300-\frac{9}{0.28} \simeq 287$ and $300-\frac{9}{0.97} \simeq 290$.

The following proposition yields the symmetric equilibrium under ambiguity of this game. The notation $[x]$ refers to the smallest integer larger or equal to $x$. For ease of notation, we will suppress the arguments of the function $\bar{n}(\alpha, \delta, R)$ and will write $\bar{n}$ for its value.

Proposition A.2 Suppose the conditions of Lemma A.1 are satisfied.

1. For $R=180$, in the unique symmetric EUA both players have beliefs:

$$
\pi^{*}(180)=1 \text {. }
$$

In response, both players choose $n_{1}^{*}=n_{2}^{*}=180$. 
2. For $R=5$, in the unique symmetric EUA both players have beliefs:

where

$$
\begin{aligned}
\pi^{*}([\bar{n}]) & =\left(1+\frac{\alpha \delta}{1-\delta}\right) \cdot \frac{299-[\bar{n}]}{299-[\bar{n}]+R} \\
\pi^{*}(299) & =\frac{R}{(299-[\bar{n}]+R)}-\frac{\alpha \delta}{(1-\delta)} \cdot \frac{(299-[\bar{n}])}{(299-[\bar{n}]+R)},
\end{aligned}
$$

$$
\bar{n}(\alpha, \delta, R):=300-\frac{(1-\delta)}{\alpha \delta}(2 R-1)
$$

In response, both players choose $n_{1}^{*}, n_{2}^{*} \in\{[\bar{n}], 299\}$.

Proof. The equilibrium beliefs $\pi^{*}$ of an EUA must make players indifferent between claiming $[\bar{n}]$ and 299. Clearly, all strategies which are not best responses will be played with probability zero. Hence, we can set $\pi^{*}(n)=0$ for all $n \notin\{[\bar{n}], 299\}$. For notational convenience, let $\pi^{*}([\bar{n}])=\beta$ and $\pi^{*}(299)=1-\beta$. In an EUA the following equation must be satisfied:

$$
V_{1}\left([\bar{n}] ; \alpha, \delta, \pi^{*}\right)-V_{1}\left(299 ; \alpha, \delta, \pi^{*}\right)=0 .
$$

Expanding, one has

$$
\begin{aligned}
& \delta\{\alpha([\bar{n}]+R)+(1-\alpha)(180-R)\}+(1-\delta) \cdot\left\{[\bar{n}] \cdot \pi^{*}([\bar{n}])+([\bar{n}]+R) \cdot \pi^{*}(299)\right\} \\
& -\delta\{\alpha(299+R)+(1-\alpha)(180-R)\}+(1-\delta) \cdot\{([\bar{n}]-R) \cdot \pi([\bar{n}])+(299) \cdot \pi(299)\} \\
= & \delta \alpha([\bar{n}]-299)+(1-\delta) \cdot\{R \cdot \beta+([\bar{n}]-299+R) \cdot(1-\beta)\}=0 .
\end{aligned}
$$

Solving for $\beta$, we obtain

$$
\beta=\left(1+\frac{\alpha \delta}{1-\delta}\right) \cdot \frac{299-[\bar{n}]}{299-[\bar{n}]+R} .
$$

Hence,

$$
\begin{aligned}
\pi^{*}([\bar{n}]) & =\left(1+\frac{\alpha \delta}{1-\delta}\right) \cdot \frac{299-[\bar{n}]}{299-[\bar{n}]+R} \\
\pi^{*}(299) & =\frac{R}{(299-[\bar{n}]+R)}-\frac{\alpha \delta}{(1-\delta)} \cdot \frac{(299-[\bar{n}])}{(299-[\bar{n}]+R)}
\end{aligned}
$$




\section{Appendix B. Matching Pennies}

Proposition 3.2 Suppose players's beliefs are given by a neo-additive capacity with parameters $\alpha, \delta$ in the $K W$-range.

1. In game D there is a unique EUA where each player is equally likely to use either strategy i.e. $\nu_{1}(T)=\nu_{1}(B)$ and $\nu_{2}(L)=\nu_{2}(R)$.

2. In game E there is a unique EUA in which $T$ is the best response of player 1 and $R$ is the best response of player 2.

Proof of Proposition 3.2 Let $\mathbf{x}$ be the payoff of Player 1 at the strategy combination $\langle T, L\rangle$. Consider first Player 1's pay-offs: ${ }^{22}$

$$
\begin{aligned}
V_{1}(T)-V_{1}(B)= & \delta[\alpha \mathbf{x}+(1-\alpha) 40]+(1-\delta)[\mathbf{x} \cdot \pi(L)+40 \cdot \pi(R)] \\
& -\delta[\alpha 80+(1-\alpha) 40]-(1-\delta)[40 \cdot \pi(L)+80 \cdot \pi(R)] \\
= & \delta \alpha(\mathbf{x}-80)+(1-\delta)[\mathbf{x} \cdot \pi(L)-40] .
\end{aligned}
$$

Similarly, for Player 2 we obtain:

$$
\begin{aligned}
V_{2}(L)-V_{2}(R)= & \delta[\alpha 80+(1-\alpha) 40]+(1-\delta)[40 \cdot \pi(T)+80 \cdot \pi(B)] \\
& -\delta[\alpha 80+(1-\alpha) 40]-(1-\delta)[80 \cdot \pi(T)+40 \cdot \pi(B)] \\
= & (1-\delta) 40 \cdot(\pi(B)-\pi(T))=(1-\delta) 80\left(\frac{1}{2}-\pi(T)\right) .
\end{aligned}
$$

In game $B$, where $\mathbf{x}=\mathbf{8 0}$,

$$
\begin{aligned}
& \pi^{*}(L)=\pi^{*}(R)=\frac{1}{2}, \\
& \pi^{*}(T)=\pi^{*}(B)=\frac{1}{2},
\end{aligned}
$$

is the only EUA for any degree of optimism $\alpha$ and any degree of ambiguity $\delta$.

When $\mathbf{x}=320, V_{1}(T)-V_{1}(B)=240 \delta a+(1-\delta) 320\left(\pi_{1}(L)-\frac{1}{8}\right) \geqslant 240 \delta a-(1-\delta) 40$. Thus if

$$
\frac{\delta \alpha}{1-\delta} \geqslant \frac{1}{6}
$$

$T$ will be preferred to $B$ for any beliefs about player 2 's behaviour (i.e. $T$ will be a best response whatever the value of $\left.\pi_{1}(L)\right)$. Provided $\alpha$ and $\delta$ are in the KW-range $\frac{1}{6} \leqslant 0.27 \leqslant \frac{\alpha \delta}{1-\delta} \leqslant 0.97$,

22 For convenience we suppress the $\operatorname{arguments} \alpha, \delta$ and $\pi$. 
hence inequality (B-1) will hold for all such parameter values.

In equilibrium, player 2's beliefs must satisfy $\nu_{2}(B)=0$, which implies:

$$
\begin{aligned}
& V_{2}(L)=\delta \alpha 80+\delta(1-\alpha) 40+(1-\delta) 40 \\
& V_{2}(R)=\delta \alpha 80+\delta(1-\alpha) 40+(1-\delta) 80 .
\end{aligned}
$$

Hence $L$ is a best response for 2 for $0<\alpha \leqslant 1,0<\delta \leqslant 1$.

Thus it follows that for parameters in the KW-range Game E has a unique equilibrium with ambiguity in which 1 plays $T$ and 2 plays $R$.

\section{Appendix C. A Coordination Game with a Secure Option}

Proposition 3.3 For the coordination game with a secure option:

1. In game $F$ both $\langle H, H\rangle$ and $\langle L, L\rangle$ are EUA for all parameters in the $K W$-range.

2. In game $G$,

a. $\langle H, H\rangle$ is an EUA for $\alpha, \delta$ in the $K W$-range provided $0.82 \geqslant \frac{\delta \alpha}{1-\delta}$.

b. $\langle L, L\rangle$ is an EUA for all parameters in the $K W$-range.

Proof of Proposition 3.3 Conditions for $\langle H, H\rangle$ to be an equilibrium in Game F Suppose that player 2 'believes' player 1 will play $H$, i.e. $H$ is the support of his beliefs. Then her (Choquet) expected utility is: $V_{2}(H)=\delta \alpha 180+(1-\delta) 180, V_{2}(L)=\delta \alpha 90$ and $V_{2}(S)=40$.

$$
\begin{aligned}
& V_{2}(H)>V_{2}(L) \text { for all } \alpha, \delta, 0 \leqslant \alpha \leqslant 1,0 \leqslant \delta \leqslant 1 . \\
& V_{2}(H) \geqslant V_{2}(S) \Longleftrightarrow \delta \alpha 9+(1-\delta) 9 \geqslant 2 .
\end{aligned}
$$

One can check this inequality holds for all $\alpha \delta$ in the KW range.

Suppose that player 1 'believes' player 2 will play $H$, then her (Choquet) expected utility is: $V_{1}(H)=\delta \alpha 180+(1-\delta) 180$ and $V_{1}(L)=\delta \alpha 90$. Hence $V_{1}(H)>V_{1}(L)$ for all $\alpha, \delta$, $0<\alpha \leqslant 1,0<\delta \leqslant 1$.

Conditions for $\langle L, L\rangle$ to be an equilibrium in Game $\mathbf{F} \quad$ Suppose that player 2 'believes' player 1 will play $L$. Then his (Choquet) expected utility is: $V_{2}(H)=\delta \alpha 180, V_{2}(L)=\delta \alpha 90+$ $(1-\delta) 90$ and $V_{2}(S)=40$. Thus $V_{2}(L) \geqslant V_{2}(S) \Longleftrightarrow \delta \alpha 9+(1-\delta) 9 \geqslant 4$ and $V_{2}(L) \geqslant$ $V_{2}(H) \Longleftrightarrow \delta \alpha+(1-\delta) \geqslant 2 \delta \alpha \Longleftrightarrow 1 \geqslant \frac{\delta \alpha}{1-\delta}$. One can check that both of these inequalities 
hold for all $\alpha \delta$ in the KW range.

Conditions for $\langle H, H\rangle$ to be an equilibrium in Game $\mathbf{G} \quad$ Suppose that player 1 'believes' player 2 will play $H$. Then her (Choquet) expected utility is: $V_{1}(H)=\delta \alpha 180+(1-\delta) 180$ and $V_{1}(L)=\delta \alpha 400$. For $H$ to be a best response we require: $\delta \alpha 9+(1-\delta) 9 \geqslant \delta \alpha 20$ or $0.82=\frac{9}{11} \geqslant \frac{\delta \alpha}{1-\delta}$.

Suppose that player 2 'believes' player 1 will play $H$. Then $H$ will be a best response for player 2 whenever the parameters are in the KW range. The reasoning for Game $F$ applies here since the pay-offs of player 2 are the same in the two games.

Conditions for $\langle L, L\rangle$ to be an equilibrium in Game $\mathbf{G} \quad$ Suppose that player 1 'believes' player 2 will play $L$. Then her (Choquet) expected utility is: $V_{1}(H)=\delta \alpha 180$ and $V_{1}(L)=$ $\delta \alpha 400+(1-\delta) 90$. Hence $V_{1}(L)>V_{1}(H)$ for all $\alpha, \delta$ such that $0<\alpha \leqslant 1,0<\delta \leqslant 1$.

If player 2 'believes' player 1 will play $L$, then $L$ is a best response for player 2 whenever the parameters are in the KW-range. As before the reasoning for Game $F$ applies here. Thus $\langle L, L\rangle$ is an equilibrium in Game $\mathrm{G}$ for all $\alpha \delta$ in the $\mathrm{KW}$ range. 


\begin{tabular}{|c|c|c|}
\hline Nr. & Author & Title \\
\hline 08-08 & $\begin{array}{l}\text { Jürgen Eichberger } \\
\text { David Kelsey }\end{array}$ & Are the Treasures of Game Theory Ambiguous? \\
\hline 08-07 & $\begin{array}{l}\text { Jürgen Eichberger } \\
\text { Ani Guerdjikova }\end{array}$ & Multiple Priors as Similarity Weighted Frequencies \\
\hline $08-06$ & $\begin{array}{l}\text { Jörg Oechssler } \\
\text { Andreas Roider } \\
\text { Patrick W. Schmitz }\end{array}$ & Cooling-Off in Negotiations - Does It Work? \\
\hline 08-05 & $\begin{array}{l}\text { Jörg Oechssler } \\
\text { Andreas Roider } \\
\text { Patrick W. Schmitz }\end{array}$ & Cognitive Abilities and Behavioral Biases \\
\hline 08-04 & Julian Rode & $\begin{array}{l}\text { Truth and trust in communication - Experiments on } \\
\text { the effect of a competitive context }\end{array}$ \\
\hline $08-03$ & Volker Stocké & $\begin{array}{l}\text { Educational Decisions as Rational Choice? An } \\
\text { Empirical Test of the Erikson-Jonsson Model for } \\
\text { Explaining Educational Attainment }\end{array}$ \\
\hline 08-02 & $\begin{array}{l}\text { Siegfried K. Berninghaus } \\
\text { Karl-Martin Ehrhart } \\
\text { Marion Ott }\end{array}$ & $\begin{array}{l}\text { Myopically Forward-Looking Agents in a Network } \\
\text { Formation Game: Theory and Experimental } \\
\text { Evidence }\end{array}$ \\
\hline $08-01$ & $\begin{array}{l}\text { Sascha Huber } \\
\text { Thomas Gschwend } \\
\text { Michael F. Meffert } \\
\text { Franz Urban Pappi }\end{array}$ & $\begin{array}{l}\text { Erwartungsbildung über den Wahlausgang und ihr } \\
\text { Einfluss auf die Wahlentscheidung }\end{array}$ \\
\hline $07-76$ & $\begin{array}{l}\text { Michael Bremert } \\
\text { Dennis Voeller } \\
\text { Nicole Zein }\end{array}$ & $\begin{array}{l}\text { Interdependencies between Elements of } \\
\text { Governance and Auditing: Evidence from Germany }\end{array}$ \\
\hline $07-75$ & $\begin{array}{l}\text { Jannis Bischof } \\
\text { Jens Wüstemann }\end{array}$ & $\begin{array}{l}\text { How Does Fair Value Measurement under IAS } 39 \\
\text { Affect Disclosure Choices of European Banks? }\end{array}$ \\
\hline $07-74$ & $\begin{array}{l}\text { Markus Glaser } \\
\text { Philipp Schäfers } \\
\text { Martin Weber }\end{array}$ & $\begin{array}{l}\text { Managerial Optimism and Corporate Investment: Is } \\
\text { the CEO Alone Responsible for the Relation? }\end{array}$ \\
\hline $07-73$ & $\begin{array}{l}\text { Jannis Bischof } \\
\text { Michael Ebert }\end{array}$ & $\begin{array}{l}\text { IAS } 39 \text { and Biases in the Risk Perception of } \\
\text { Financial Instruments }\end{array}$ \\
\hline
\end{tabular}




\begin{tabular}{|c|c|c|}
\hline Nr. & Author & Title \\
\hline $07-72$ & $\begin{array}{l}\text { Susanne Abele } \\
\text { Garold Stasser }\end{array}$ & $\begin{array}{l}\text { Continuous and Step-level Pay-off Functions in } \\
\text { Public Good Games: A Conceptual Analysis }\end{array}$ \\
\hline $07-71$ & $\begin{array}{l}\text { Julian Rode } \\
\text { Marc Le Menestrel }\end{array}$ & The role of power for distributive fairness \\
\hline $07-70$ & $\begin{array}{l}\text { Markus Glaser } \\
\text { Martin Weber }\end{array}$ & $\begin{array}{l}\text { Why inexperienced investors do not learn: They do } \\
\text { not know their past portfolio performance }\end{array}$ \\
\hline $07-69$ & $\begin{array}{l}\text { Jose Apesteguia } \\
\text { Steffen Huck } \\
\text { Jörg Oechssler } \\
\text { Simon Weidenholzer }\end{array}$ & $\begin{array}{l}\text { Imitation and the Evolution of Walrasian Behavior: } \\
\text { Theoretically Fragile but Behaviorally Robust }\end{array}$ \\
\hline $07-68$ & $\begin{array}{l}\text { Damian S. Damianov } \\
\text { Jörg Oechssler } \\
\text { Johannes Gerd Becker }\end{array}$ & $\begin{array}{l}\text { Uniform vs. Discriminatory Auctions with Variable } \\
\text { Supply - Experimental Evidence }\end{array}$ \\
\hline $07-67$ & $\begin{array}{l}\text { Dirk Simons } \\
\text { Barbara E. Weißenberger }\end{array}$ & $\begin{array}{l}\text { Die Konvergenz von externem und internem } \\
\text { Rechnungswesen ñKritische Faktoren für die } \\
\text { Entwicklung einer partiell integrierten } \\
\text { Rechnungslegung aus theoretischer Sichtñ }\end{array}$ \\
\hline $07-66$ & $\begin{array}{l}\text { Alexander Ludwig } \\
\text { Alexander Zimper }\end{array}$ & Attitude polarization \\
\hline $07-65$ & $\begin{array}{l}\text { Alexander Ludwig } \\
\text { Alexander Zimper }\end{array}$ & $\begin{array}{l}\text { A Parsimonious Model of Subjective Life } \\
\text { Expectancy }\end{array}$ \\
\hline $07-64$ & $\begin{array}{l}\text { Michael F. Meffert } \\
\text { Thomas Gschwend }\end{array}$ & $\begin{array}{l}\text { Voting for Coalitions? The Role of Coalition } \\
\text { Preferences and Expectations in Voting Behavior }\end{array}$ \\
\hline $07-63$ & $\begin{array}{l}\text { Michael F. Meffert } \\
\text { Thomas Gschwend }\end{array}$ & $\begin{array}{l}\text { Polls, Coalition Signals, and Strategic Voting: An } \\
\text { Experimental Investigation of Perceptions and } \\
\text { Effects }\end{array}$ \\
\hline $07-62$ & $\begin{array}{l}\text { Peter Dürsch } \\
\text { Maros Servátka }\end{array}$ & Risky Punishment and Reward in the Prisoner \\
\hline $07-61$ & $\begin{array}{l}\text { Wendelin Schnedler } \\
\text { Radovan Vadovic }\end{array}$ & Legitimacy of Control \\
\hline
\end{tabular}




\begin{tabular}{|c|c|c|}
\hline Nr. & Author & Title \\
\hline $07-60$ & Volker Stocké & $\begin{array}{l}\text { Strength, Sources, and Temporal Development of } \\
\text { Primary Effects of Families' Social Status on } \\
\text { Secondary School Choice }\end{array}$ \\
\hline $07-59$ & $\begin{array}{l}\text { Christopher Koch } \\
\text { Martin Weber } \\
\text { Jens Wüstemann }\end{array}$ & $\begin{array}{l}\text { Can Auditors Be Independent? - Experimental } \\
\text { Evidence }\end{array}$ \\
\hline $07-58$ & Sylvain Béal & PERCEPTRON VERSUS AUTOMATON\&8727; \\
\hline $07-57$ & $\begin{array}{l}\text { Sylvain Béal } \\
\text { Jacques Durieu } \\
\text { Philippe Solal }\end{array}$ & Farsighted Coalitional Stability in TU-games \\
\hline $07-56$ & $\begin{array}{l}\text { Alen Nosic } \\
\text { Martin Weber }\end{array}$ & $\begin{array}{l}\text { Determinants of Risk Taking Behavior: The role of } \\
\text { Risk Attitudes, Risk Perceptions and Beliefs }\end{array}$ \\
\hline $07-55$ & $\begin{array}{l}\text { Michael F. Meffert } \\
\text { Thomas Gschwend }\end{array}$ & $\begin{array}{l}\text { Strategic Voting under Proportional Representation } \\
\text { and Coalition Governments: A Simulation and } \\
\text { Laboratory Experiment }\end{array}$ \\
\hline $07-54$ & Klaus Fiedler & $\begin{array}{l}\text { Pseudocontingencies - A key paradigm for } \\
\text { understanding adaptive cognition }\end{array}$ \\
\hline $07-53$ & $\begin{array}{l}\text { Florian Kutzner } \\
\text { Peter Freytag } \\
\text { Tobias Vogel } \\
\text { Klaus Fiedler }\end{array}$ & $\begin{array}{l}\text { Base-rate neglect based on base-rates in } \\
\text { experience-based contingency learning }\end{array}$ \\
\hline $07-52$ & $\begin{array}{l}\text { Klaus Fiedler } \\
\text { Yaakov Kareev }\end{array}$ & $\begin{array}{l}\text { Implications and Ramifications of a Sample-Size } \\
\text { Approach to Intuition }\end{array}$ \\
\hline $07-51$ & Klaus Fiedler & $\begin{array}{l}\text { The Ultimate Sampling Dilemma in } \\
\text { Experience-Based Decision Making }\end{array}$ \\
\hline $07-50$ & $\begin{array}{l}\text { Jürgen Eichberger } \\
\text { David Kelsey }\end{array}$ & Ambiguity \\
\hline $07-49$ & Tri Vi Dang & Information Acquisition in Double Auctions \\
\hline $07-48$ & Clemens Kroneberg & $\begin{array}{l}\text { Wertrationalität und das Modell der } \\
\text { Frame-Selektion }\end{array}$ \\
\hline
\end{tabular}




\begin{tabular}{|c|c|c|}
\hline Nr. & Author & Title \\
\hline $07-47$ & $\begin{array}{l}\text { Dirk Simons } \\
\text { Nicole Zein }\end{array}$ & Audit market segmentation and audit quality \\
\hline $07-46$ & $\begin{array}{l}\text { Sina Borgsen } \\
\text { Martin Weber }\end{array}$ & $\begin{array}{l}\text { False Consensus and the Role of Ambiguity in } \\
\text { Predictions of Othersí Risky Preferences }\end{array}$ \\
\hline $07-45$ & $\begin{array}{l}\text { Martin Weber } \\
\text { Frank Welfens }\end{array}$ & $\begin{array}{l}\text { An Individual Level Analysis of the Disposition } \\
\text { Effect: Empirical and Experimental Evidence }\end{array}$ \\
\hline $07-44$ & $\begin{array}{l}\text { Martin Weber } \\
\text { Frank Welfens }\end{array}$ & $\begin{array}{l}\text { The Repurchase Behavior of Individual Investors: } \\
\text { An Experimental Investigation }\end{array}$ \\
\hline $07-43$ & $\begin{array}{l}\text { Manel Baucells } \\
\text { Martin Weber } \\
\text { Frank Welfens }\end{array}$ & $\begin{array}{l}\text { Reference Point Formation Over Time: A } \\
\text { Weighting Function Approach }\end{array}$ \\
\hline $07-42$ & $\begin{array}{l}\text { Martin Weber } \\
\text { Frank Welfens }\end{array}$ & $\begin{array}{l}\text { How do Markets React to Fundamental Shocks? An } \\
\text { Experimental Analysis on Underreaction and } \\
\text { Momentum }\end{array}$ \\
\hline $07-41$ & $\begin{array}{l}\text { Ernst Maug } \\
\text { Ingolf Dittmann }\end{array}$ & $\begin{array}{l}\text { Lower Salaries and No Options: The Optimal } \\
\text { Structure of Executive Pay }\end{array}$ \\
\hline $07-40$ & $\begin{array}{l}\text { Ernst Maug } \\
\text { Ingolf Dittmann } \\
\text { Christoph Schneider }\end{array}$ & Bankers and the Performance of German Firms \\
\hline 07-39 & $\begin{array}{l}\text { Michael Ebert } \\
\text { Nicole Zein }\end{array}$ & $\begin{array}{l}\text { Wertorientierte Vergütung des Aufsichtsrats - } \\
\text { Auswirkungen auf den Unternehmenswert }\end{array}$ \\
\hline $07-38$ & $\begin{array}{l}\text { Ingolf Dittmann } \\
\text { Ernst Maug } \\
\text { Christoph Schneider }\end{array}$ & $\begin{array}{l}\text { How Preussag became TUI: Kissing too Many } \\
\text { Toads Can Make You a Toad }\end{array}$ \\
\hline $07-37$ & $\begin{array}{l}\text { Ingolf Dittmann } \\
\text { Ernst Maug }\end{array}$ & $\begin{array}{l}\text { Valuation Biases, Error Measures, and the } \\
\text { Conglomerate Discount }\end{array}$ \\
\hline $07-36$ & $\begin{array}{l}\text { Ingolf Dittmann } \\
\text { Ernst Maug } \\
\text { Oliver Spalt }\end{array}$ & $\begin{array}{l}\text { Executive Stock Options when Managers are } \\
\text { Loss-Averse }\end{array}$ \\
\hline $07-35$ & $\begin{array}{l}\text { Ernst Maug } \\
\text { Kristian Rydqvist }\end{array}$ & $\begin{array}{l}\text { Do Shareholders Vote Strategically? Voting } \\
\text { Behavior, Proposal Screening, and Majority Rules }\end{array}$ \\
\hline
\end{tabular}

